Article

\title{
Design and Experimental Study of HTSG for Waste to Energy: Analysis of Pressure Difference
}

\author{
Jeachul Jang ${ }^{(D)}$, Sunhee Oh, Chongpyo Cho and Seong-Ryong Park * iD \\ Energy Efficiency and Materials Research Division, Korea Institute of Energy Research (KIER), \\ Daejeon 34129, Korea; airef2009@kier.re.kr (J.J.); ohsunhee@kier.re.kr (S.O.); cnsever@kier.re.kr (C.C.) \\ * Correspondence: srpark@kier.re.kr; Tel.: +82-42-860-3224
}

Received: 18 June 2018; Accepted: 5 July 2018; Published: 11 July 2018

check for updates

\begin{abstract}
The purpose of the present study is to analyze pressure difference changes inside a high-temperature steam generator (HTSG), which produces steam using the heat generated by waste incineration and decreases the pressure of the produced steam while increasing its temperature. The high-temperature, low-pressure steam produced by a HTSG is used for hydrogen production. Therefore, the steam temperature must be at least $700{ }^{\circ} \mathrm{C}$, and the pressure must be lower than $300 \mathrm{kPa}$; hence, a device is needed to increase the steam temperature in the boiler and decrease the steam pressure. The physical behavior of the device was modeled and experimentally validated. The modeling and experimental results demonstrated good agreement when the steam was not preheated; however, an additional pressure drop required consideration of the opposite case.
\end{abstract}

Keywords: high-temperature steam generator (HTSG); superheater; waste to energy (WtE); sudden effect; pressure difference

\section{Introduction}

Waste to energy (WtE) has the advantages of reducing waste and transforming the energy obtained during incineration to a new form of useful energy [1]. In addition, the waste heat that is dissipated during incineration can be used to generate steam in a waste heat boiler, which can then be used directly or supplied to a turbine for power generation [2,3].

In cases when steam is generated and used directly near demanding locations, the steam temperature typically ranges between 125 and $180^{\circ} \mathrm{C}$ [4]. This temperature range is obtained without a superheater due to the requirements and economic feasibility. When a superheater is not installed, low-temperature corrosion needs to be considered because the water vapor in the air accelerates chemical changes $[5,6]$.

$\mathrm{WtE}$ thermochemical technology typically includes incineration, thermal gasification, and pyrolysis methods. In the incineration method, waste is burned at temperatures above $1000{ }^{\circ} \mathrm{C}$. However, the conventional temperature of the thermal gasification method is $750{ }^{\circ} \mathrm{C}$, and the conventional temperature of the pyrolysis method ranges between 300 and $800{ }^{\circ} \mathrm{C}$, which occurs at a higher pressure and in the absence of oxygen. However, the practical temperature and pressure at which the steam is produced in the waste heat boiler is approximately $400{ }^{\circ} \mathrm{C}$ and 40 bar, respectively, due to high-temperature corrosion problems [7,8]. Extensive research on materials has been recently conducted to overcome this challenge. Zieliński et al. [9] introduced a material with an austenitic structure (HR6W, Sanicro 25) that has stability up to $750{ }^{\circ} \mathrm{C}$. In particular, Sanicro 25 was proven to remain stable for more than $2000 \mathrm{~h}$ at $700{ }^{\circ} \mathrm{C}$. Zeng et al. [10] investigated the tensile properties, microhardness, chemical composition distribution, and microstructure of the BTi-6431S titanium alloy, which can be used in applications up to $700^{\circ} \mathrm{C}$. Furthermore, Wright et al. [11] examined the properties of Alloy $800 \mathrm{H}$ and Alloy 617 for nuclear plants and asserted that their operating temperature range 
was $750-800^{\circ} \mathrm{C}$ in the steam generator. Dewa et al. [12] also analyzed the fatigue properties of Alloy 617 and stated that its maximum design temperature was $950^{\circ} \mathrm{C}$.

Among the technologies available for hydrogen production, the operating conditions and characteristics of fuel cells vary depending on their constituent materials. Some examples include the electrolyte-type alkaline fuel cell, the phosphoric acid fuel cell, the polymer electrolyte membrane fuel cell, the molten carbonate fuel cell, and the solid oxide fuel cell (SOFC). The objective of this work is to produce steam for hydrogen production using heat, and thus the SOFC is considered, as it has an operating temperature range of $600-1000{ }^{\circ} \mathrm{C}$ [13]. In addition, the minimum operating temperature of the SOFC is $700{ }^{\circ} \mathrm{C}$, and the efficiency increases along with the heat source temperature [14].

The use of hydrogen and power generation technologies that exploit the steam obtained from the heat generated during waste incineration is expected to help reduce the effects of global warming and environmental pollution. Despite their advantages, hydrogen production technologies that leverage wastes have not yet been commercialized owing to the lack of advanced technology required to generate the high-temperature steam (greater than $700{ }^{\circ} \mathrm{C}$ ) using waste.

Therefore, this paper presents the design of a high-temperature steam generator (HTSG) having a structure that can be inserted into an incinerator to produce high-temperature steam over $700{ }^{\circ} \mathrm{C}$. The steam passing through the HTSG is designed to be heated and expanded because the pressure must be reduced due to SOFC durability. The pressure characteristics of the proposed HTSG are analyzed herein.

\section{High-Temperature Steam Generator (HTSG) Design}

When the steam generated using waste incineration heat is used directly, the steam temperature ranges between 125 and $180{ }^{\circ} \mathrm{C}$ [4]. Therefore, the design temperature considered herein is $151.9^{\circ} \mathrm{C}$, which corresponds to the saturation temperature at the design pressure of $500 \mathrm{kPa}$. The processes illustrated in Figure 1 are required to lower the pressure below $300 \mathrm{kPa}$ while increasing the temperature above $700{ }^{\circ} \mathrm{C}$. In Process A, the steam is first heated at the proposed inlet conditions, and the pressure is subsequently reduced. Contrarily, Process B first reduces the pressure and then heats the steam. Process A generally exhibits higher exergy than Process B. However, devices that expand the heated steam above temperatures of $700{ }^{\circ} \mathrm{C}$ will face durability issues and are considerably more expensive than those designed for relatively low-temperature ranges. As a result, the HTSG of this study is designed considering the aspects of both engineering and energy.
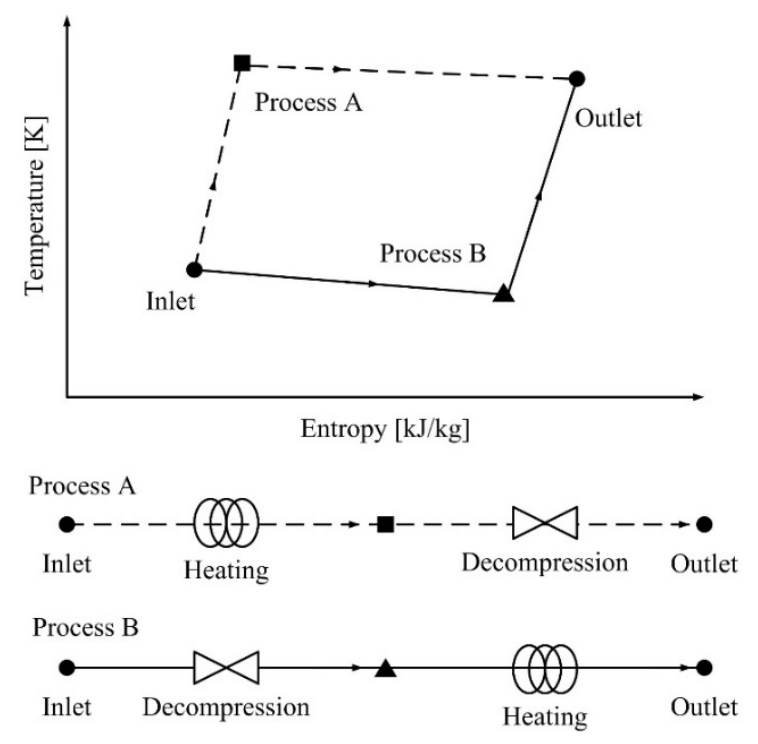

Figure 1. The processes A and B on the T-s diagram. 
In a typical closed-loop system, the pressure and temperature rise simultaneously. Since the HTSG proposed herein heats the steam using the high waste incineration heat $\left(1000^{\circ} \mathrm{C}\right)$ [7], which is a sufficient heat source, the heat transfer area can be sufficiently enlarged while forcing the pressure to drop.

Figure 2 depicts the proposed HTSG, wherein different variables are used to describe each component for the purposes of modeling the pressure drops. The heat transfer area corresponds to the total height $\left(H_{t o t}\right)$, which is installed in the combustor for the experiment. The heat transfer area was obtained from Equation (1). Where, the heat loss is generally higher at high temperature ranges. In the combustor, the heat loss was assumed to be $30 \%$, because the heat loss due to fouling is large $[15,16]$.

$$
Q_{H T S G}=U_{t o t} A_{H T S G} \Delta T_{l m}=\eta \dot{m}_{\text {ave }} C_{p, a v e}\left(T_{o}-T_{i}\right),
$$

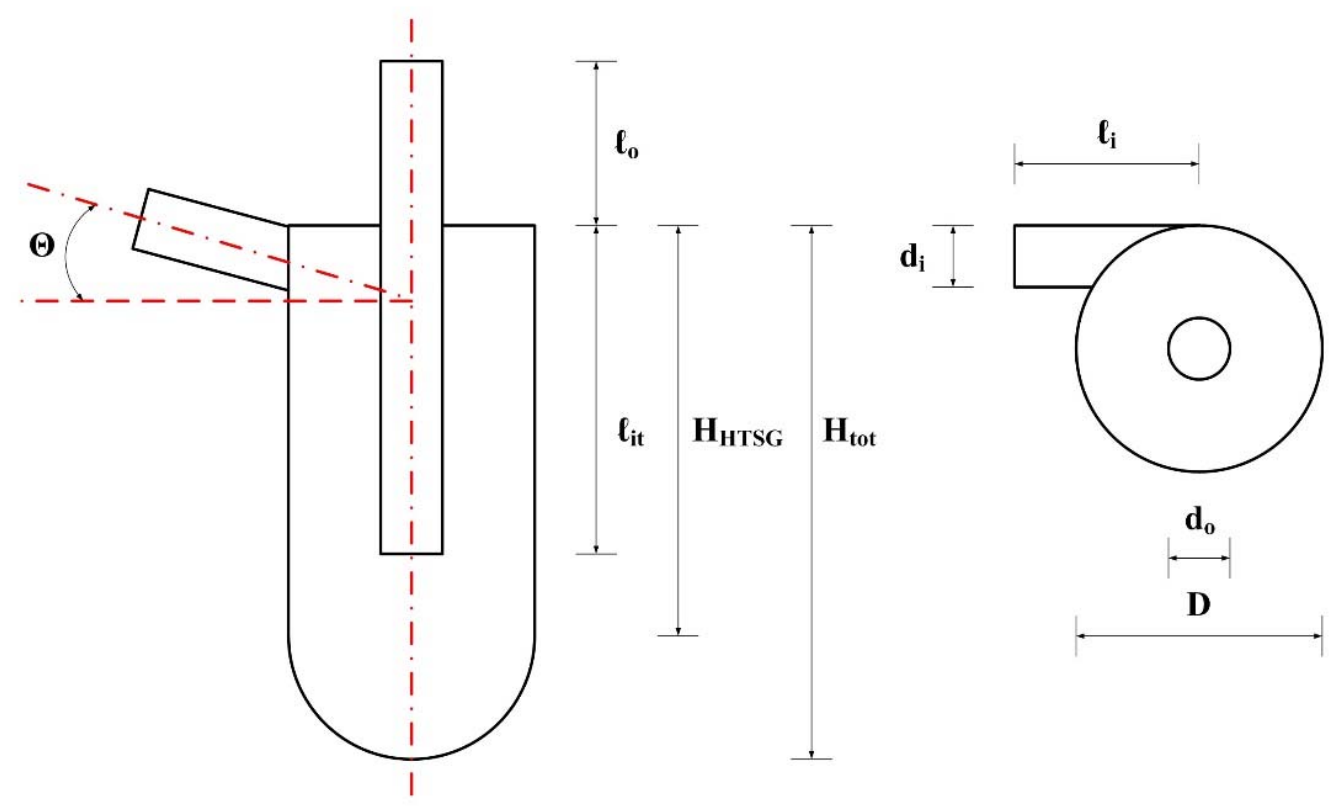

Figure 2. The schematic diagram of the high-temperature steam generator (HTSG) geometry.

Furthermore, the overall heat transfer coefficient was computed using Equation (2).

$$
U_{t o t}=\frac{1}{\frac{1}{h_{i n}}+\frac{t}{k_{m t}}+\frac{1}{h_{e x}}}
$$

The Gnielinski correlation [17] was employed to compute the Nusselt number and obtain the internal and external heat transfer coefficients (Equation (3)). The internal and external fluids were assumed to be steam and air, respectively.

$$
N u=\frac{\left(\frac{f}{8}\right)(R e-1000) \operatorname{Pr}}{1+12.7\left(\frac{f}{8}\right)^{\frac{1}{2}}\left(\operatorname{Pr}^{\frac{2}{3}}-1\right)}
$$

Here, the friction factor, $f$, is given by Equation (4) [18].

$$
f=(0.79 \ln R e-1.64)^{-2},
$$


The ratio of the diameter $(D)$ to the total height $\left(H_{t o t}\right)$ of the HTSG was calculated using Equations (1) and (4) and resulted in a ratio of 1:2. The design lengths of the diameter and total height were approximately $0.35 \mathrm{~m}$ and $0.7 \mathrm{~m}$, respectively. In general, as the length of the total height increases, the streamline length increases; however, the outlet velocity decreases at the same time. Therefore, the diameter and the total height were selected such that the flow of steam was smooth. In this study, a laboratory scale experiment was conducted beforehand, and the HTSG material was SUS310. The thermal conductivity of SUS310 is similar to that of HR6W [9] at temperatures below $400{ }^{\circ} \mathrm{C}$, as shown in Figure 3, however, its conductivity differs from that of HR6W at temperatures above $400{ }^{\circ} \mathrm{C}$. Further analysis on this discrepancy would be necessary prior to actual site applications.

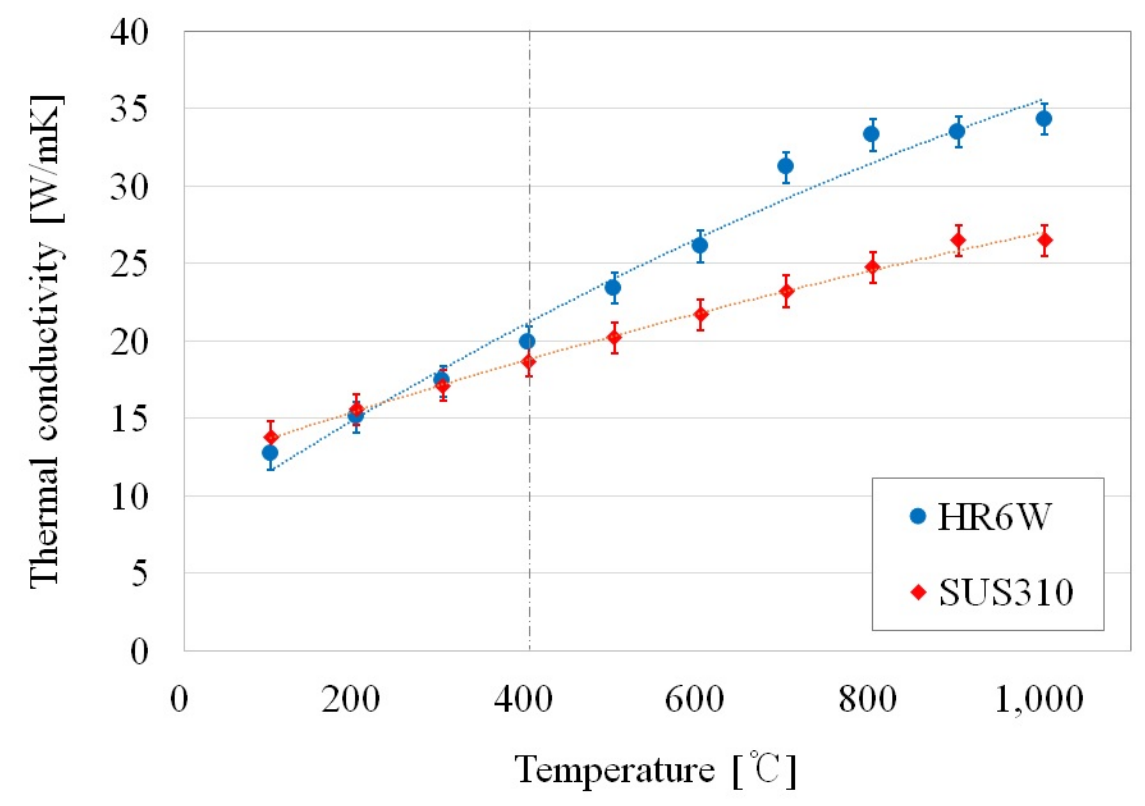

Figure 3. The thermal conductivities of the HR6W and SUS310.

\section{Pressure Difference}

The size of each HTSG component was determined to generate a reduced pressure while using the HTSG. The inner diameter $\left(d_{i}\right)$ at the inlet was approximately $0.008 \mathrm{~m}$, the outlet inner diameter $\left(d_{o}\right)$ was approximately $0.025 \mathrm{~m}$, and $\ell_{i t}$ was designed to be longer than $H_{H T S G}$. Moreover, the angle of the pipe from the entrance to the HTSG inlet was established as $5^{\circ}$. This value was selected to minimize the heat loss and to avoid pressure stagnation inside the HTSG by immediately pushing the induced vortices toward the pipe outlet. If the inlet angle of the pipe is $0^{\circ}$, the residence time of steam at the top of the HTSG increases. This decreases the velocity of steam at the outlet of the HTSG.

Figure 4 features a schematic of the parts that affect the pressure variation inside the HTSG. In Part A, the pressure drops sharply due to the sudden enlargement, and the steam flows into the HTSG body at the HTSG inlet in a tangential direction, which causes the swirling flow in Part B. The majority of the heat transfer and pressure reduction occurs in Part B. Part $C$ is designed to induce a vortex flow, which allows the fluid to exit directly towards the outlet; a slight pressure drop occurs due to friction. In Part D, the pressure is reduced by the sudden contraction. Subsequently, the pressure drop across each part can be computed as the total pressure drop, given by Equation (5). The additional pressure drop $\left(\Delta P_{t e}\right)$ due to heating was obtained from the experiment.

$$
\Delta P_{t o t}=\Delta P_{s e}+\Delta P_{s f}+\Delta P_{v f}+\Delta P_{s c}+\left(\Delta P_{t e}\right),
$$



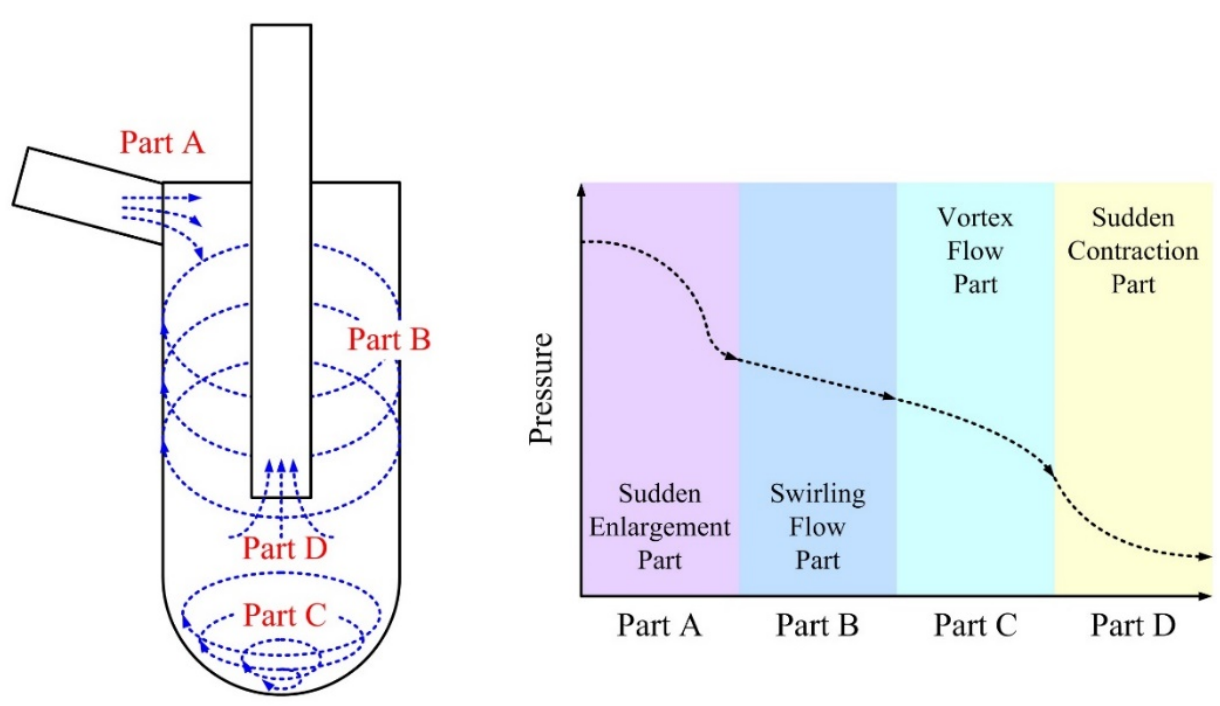

Figure 4. The streamline of the HTSG and typical pressure profile.

\subsection{Sudden Enlargement Part}

The pressure decreases abruptly when the fluid exits the pipe due to the sudden enlargement effect $[19,20]$. The HTSG proposed in this study features a shape that varies from a narrow inlet area to a wider area, thus, forcing the pressure to drop. The Borda-Carnot equation was used to compute the pressure drop (Equation (6)).

$$
\Delta P_{s e}=\xi_{s e} \frac{\gamma v_{i}^{2}}{2 g}
$$

where, $\xi_{s e}$ is the coefficient of fluid resistance obtained from Karev's experimental data [19].

\subsection{Swirling Flow Part}

Figure 5 illustrates the steam in the HTSG that swirls downwards in the tangential direction. The length of the streamline is obtained by the sum of $L$, and uniform spacing is assumed between the lines. The pressure drop is then computed using the well-known Darcy-Weisbach equation (Equation (7)) [21].

$$
\Delta P_{s f}=\rho_{\text {ave }} \frac{f_{H T S G}}{d_{\text {ave }}} \frac{v_{\text {ave }}{ }^{2}}{2} L_{s f, t o t}
$$
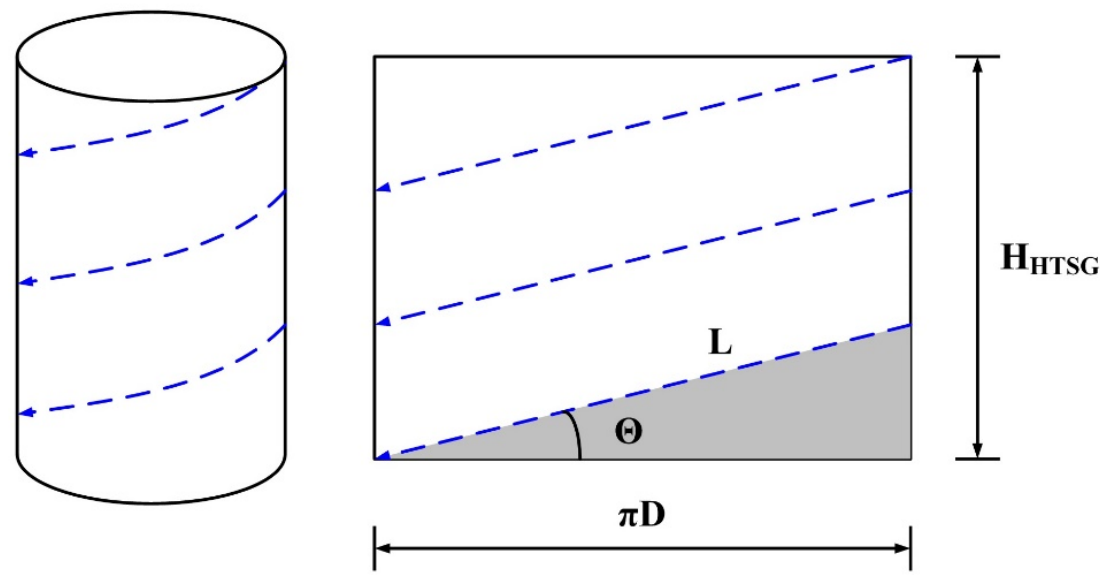

Figure 5. The streamline of the swirling flow. 


\subsection{Vortex Flow Part}

After passing through Part B, the fluid forms a vortex flow and concentrates at the bottom center as it enters Part $C$. In this case, it was assumed that the streamline of Part $C$ was extended from Part $\mathrm{B}$, and the streamline can be calculated using Equation (8) because it was assumed that $\frac{H_{H T S G}}{n}$ was constant. When the hemispherical bottom of the HTSG is differentiated infinitely, the length of each stream is linear, and the total streamline in the vortex flow region can be obtained by integration. Here, $\frac{H_{H T S G}}{n}$ is assumed to be the same as that in the swirling flow.

$$
L_{v f, t o t}=\int_{0}^{\frac{D}{2}} \sqrt{1+\left(-\frac{2 \pi}{n} \frac{x}{\sqrt{\left(\frac{D}{2}\right)^{2}-x^{2}}}\right)^{2}} d x
$$

where, $n$ is the pitch number between the stream lines. The pressure drop was computed using the Darcy-Weisbach equation [21].

\subsection{Sudden Contraction Part}

The sudden contraction as the fluid enters the pipe causes the pressure to drop, similar to the sudden enlargement pressure drop discussed previously $[19,20]$. The proposed HTSG is also designed to discharge the fluid that is concentrated at the center due to the vortex flow through the intermediate pipe. Additionally, the shape of the intermediate pipe varies from a wide to a narrower area. Subsequently, the pressure drop is obtained from Equation (9).

$$
\Delta P_{s c}=\xi_{s c} \frac{\gamma v_{o}^{2}}{2 g}
$$

where, $\xi_{s c}$ was given by the sudden contraction data in Karev's experimental data [19].

\section{Experiments}

The HTSG experimental setup contained an external combustor to heat the HTSG, as depicted in Figure 6. The steam boiler supplied steam to the HTSG, and a mass flowmeter (MF, vortex type flowmeter) was installed at the HTSG inlet. The temperature and pressure at the inlet and outlet of the HTSG, as well as those of the gas that served as a heat source, were measured. To minimize the heat loss, the combustor exterior and steam pipe were insulated with $150 \mathrm{~mm}$ of castable and $100 \mathrm{~mm}$ of fiberglass, respectively. The details of each sensor are presented in Table 1.

The experimental data were obtained by averaging the values for more than $30 \mathrm{~min}$ after the inlet/outlet temperatures, inlet/outlet pressures, and the flow rate of steam became constant. Additionally, the steam was supplied to the HTSG inlet at a constant pressure and flow rate using a pressure regulator.

Table 1. Specification of the sensors.

\begin{tabular}{ccc}
\hline Sensor & Operating Range & Uncertainty \\
\hline $\begin{array}{c}\text { Temperature sensor } \\
(\mathrm{T}, \text { k-type thermocouple) }\end{array}$ & $-200-1250{ }^{\circ} \mathrm{C}$ & $\pm 0.02{ }^{\circ} \mathrm{C}$ \\
\hline $\begin{array}{c}\text { Pressure transducer } \\
(\mathrm{P}, \text { diaphragm type) }\end{array}$ & $0-1000 \mathrm{kPa}$ & $\pm 4.71 \mathrm{kPa}$ \\
\hline $\begin{array}{c}\text { Mass flowmeter } \\
(\mathrm{MF}, \text { vortex flowmeter })\end{array}$ & $0.02-47.6 \mathrm{t} / \mathrm{h}$ & $\pm 0.35 \mathrm{~kg} / \mathrm{h}$ \\
\hline
\end{tabular}



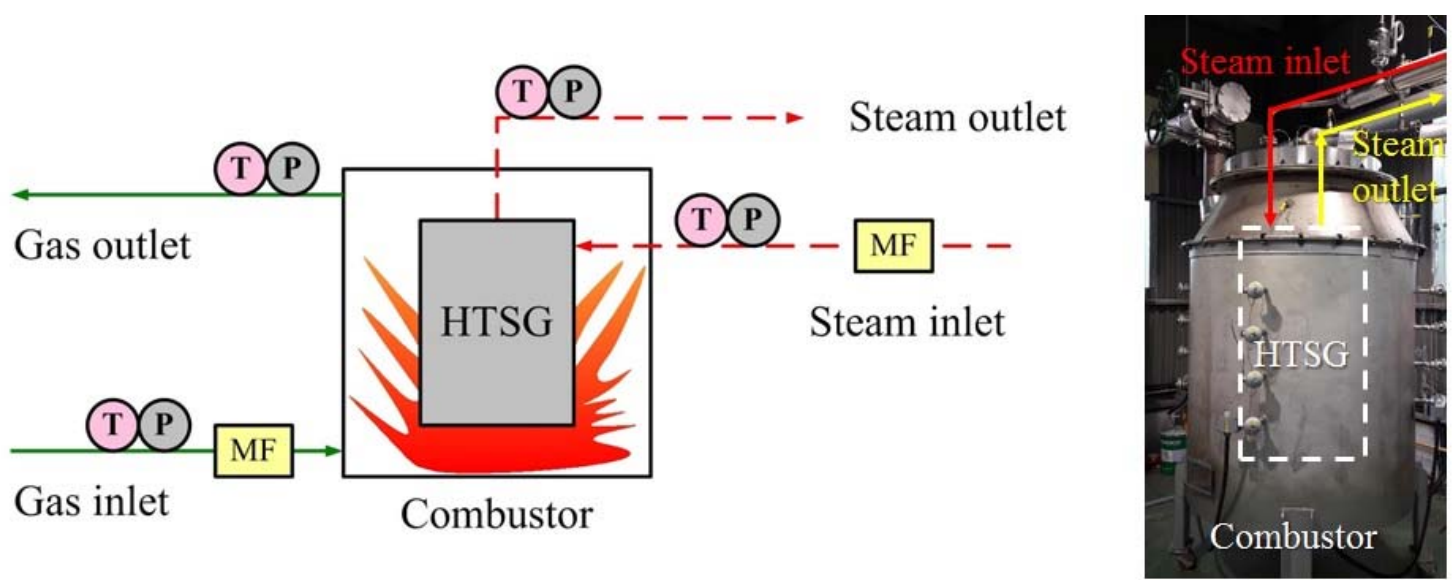

Figure 6. The schematic diagram of the HTSG tester and HTSG test rig.

\section{Results}

The HTSG pressure drop model was used to obtain the pressure drops as functions of different inlet conditions. In addition, various entrance angles and changes in the outlet pipe diameter were examined to further reduce the computed pressure drop.

\subsection{Modeling Results}

Figure 7 shows the pressure variation as a function of the Reynolds number at the HTSG inlet, which demonstrates the effect of the sudden enlargement. As the Reynolds number increases, the higher fluid velocity causes the magnitude of pressure to drop. The magnitudes of the pressure drops are expected to increase further if higher flow rates than those proposed herein are implemented.

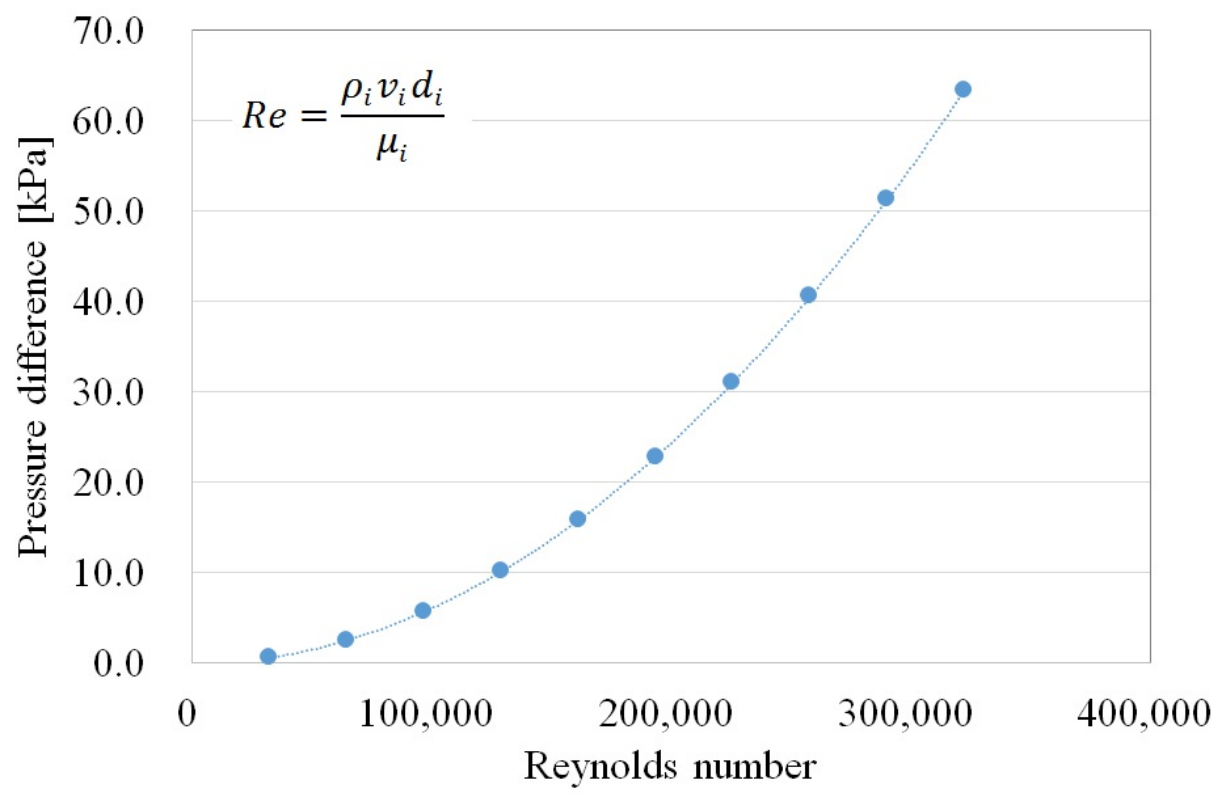

Figure 7. The pressure difference according to the Reynolds number (sudden enlargement effect).

Figure 8 displays the pressure variation in the swirling flow region. The pressure drop decreases as the Reynolds number at the inlet increases due to the reduced friction factor with increased Reynolds numbers. Subsequently, the pressure drop will increase further if the flux increases at higher inlet flow rates. Figure 9 depicts the pressure variation in the swirling flow region as a function of the inlet pipe 
entrance angle. As the entrance angle decreases, the pressure drop increases. This is because the length of streamline increases as the angle becomes smaller. However, further reduction of the entrance angle will lead to fluid retention in the upper region of the HTSG, and the pressure will stagnate; hence, care must be taken in the design process.

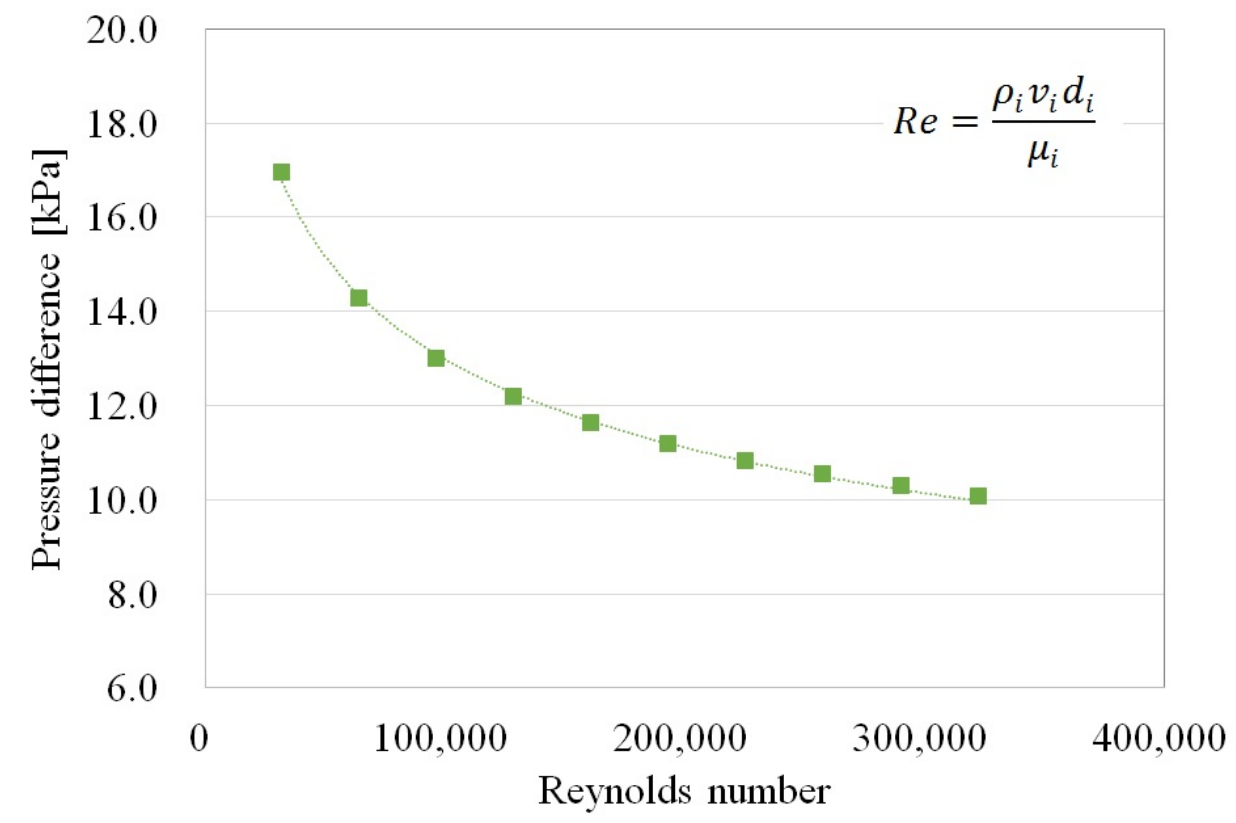

Figure 8. The pressure difference according to the Reynolds number (swirling flow effect).

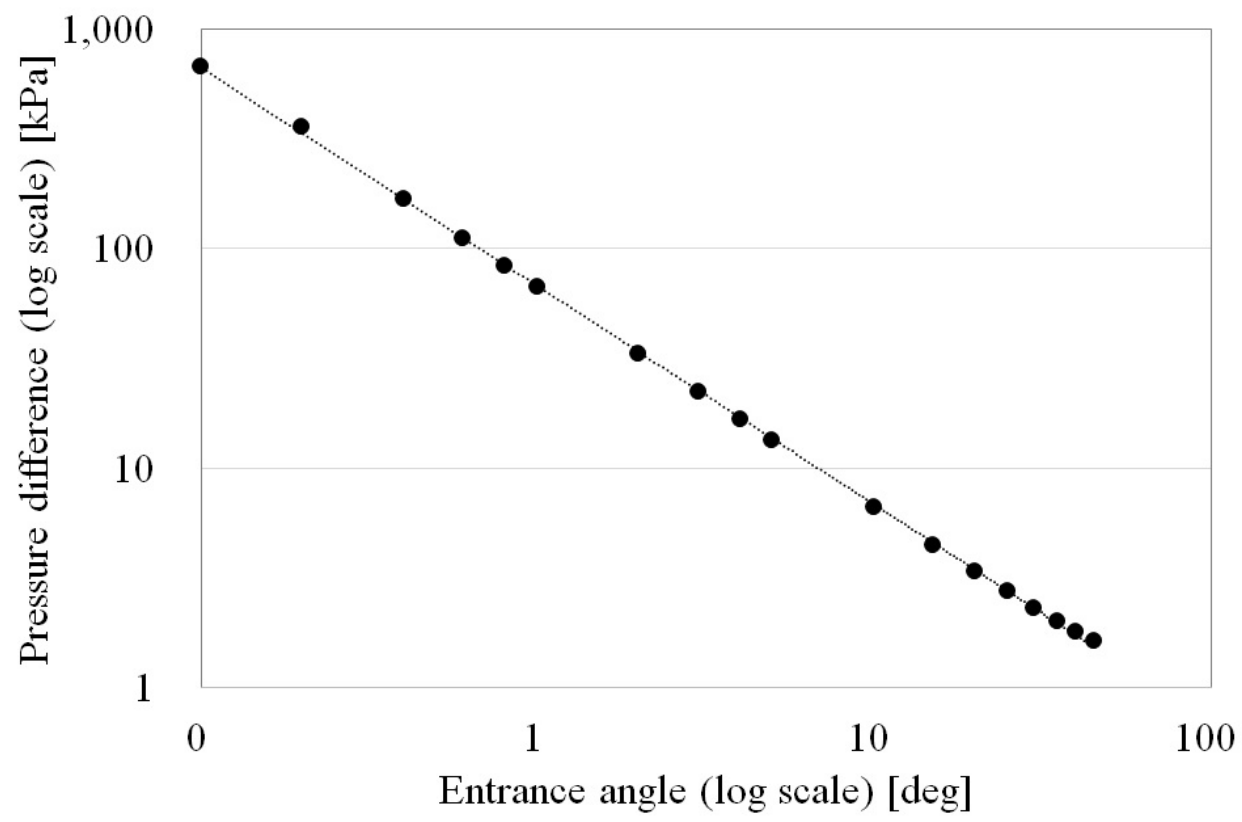

Figure 9. The pressure difference according to the entrance angle at the swirling flow part.

Figure 10 depicts the pressure variation in the vortex flow region. The pressure drop in this region is relatively smaller than the other parts due to the smaller area, and the pressure drop decreases as the Reynolds number at the inlet increases due to the reason discussed previously pertaining to the swirling flow region. 


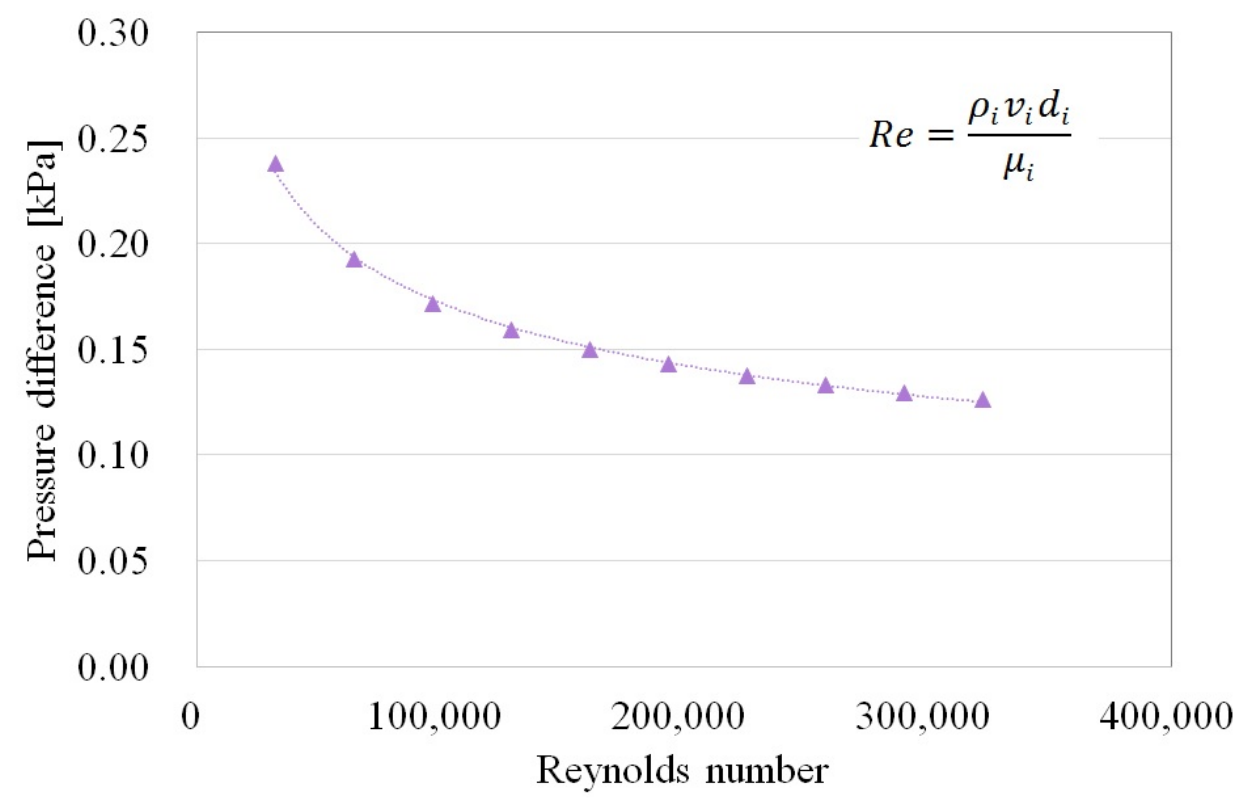

Figure 10. The pressure difference according to the Reynolds number (vortex flow effect).

Figure 11 shows the pressure variation in the sudden contraction region. This pressure drop is also small due to the relatively large size of the discharging pipe. The pressure drop increases with increasing Reynolds number, similar to the sudden enlargement region. Figure 12 depicts the pressure variation in the sudden contraction region with respect to different outlet pipe diameters, where the pressure drop increases as the pipe diameter decreases. However, if the outlet pipe diameter is further reduced, the pressure inside the HTSG will stagnate; thus, careful consideration is required in the design process.

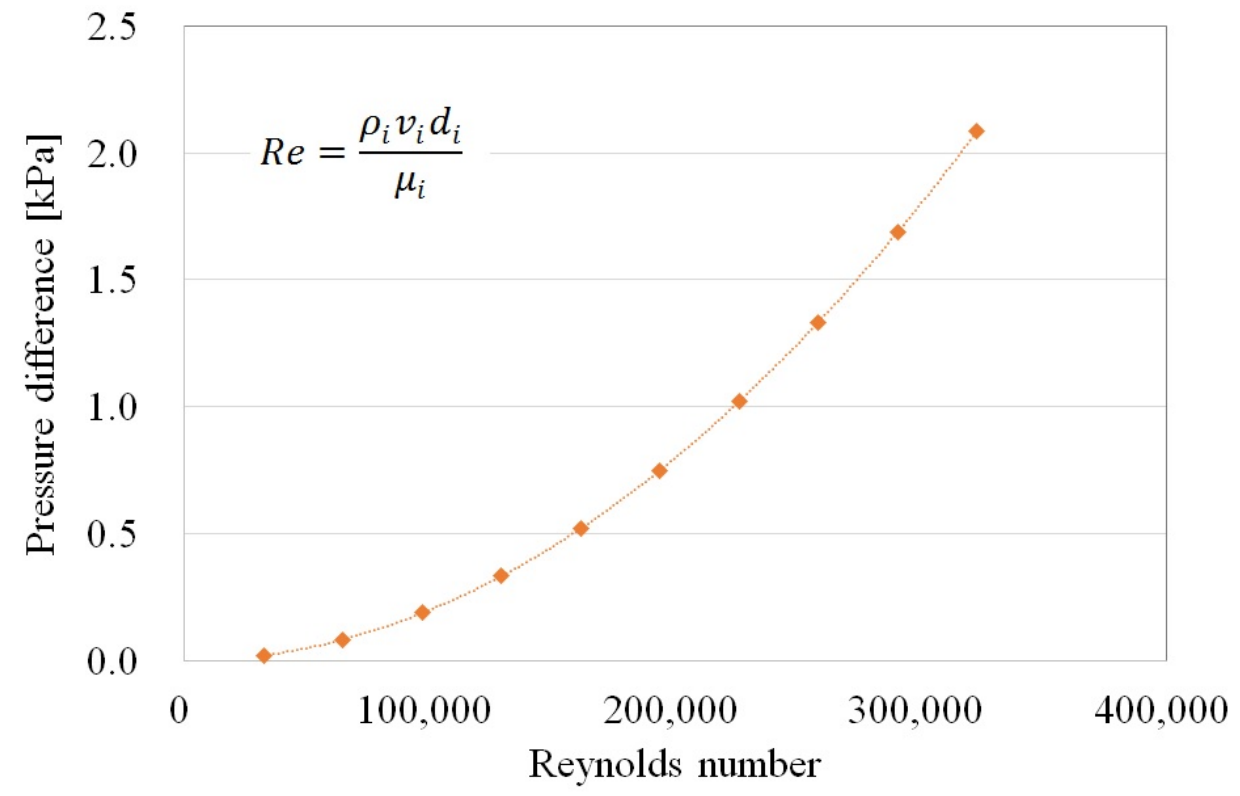

Figure 11. The pressure difference according to the Reynolds number (sudden contraction effect). 


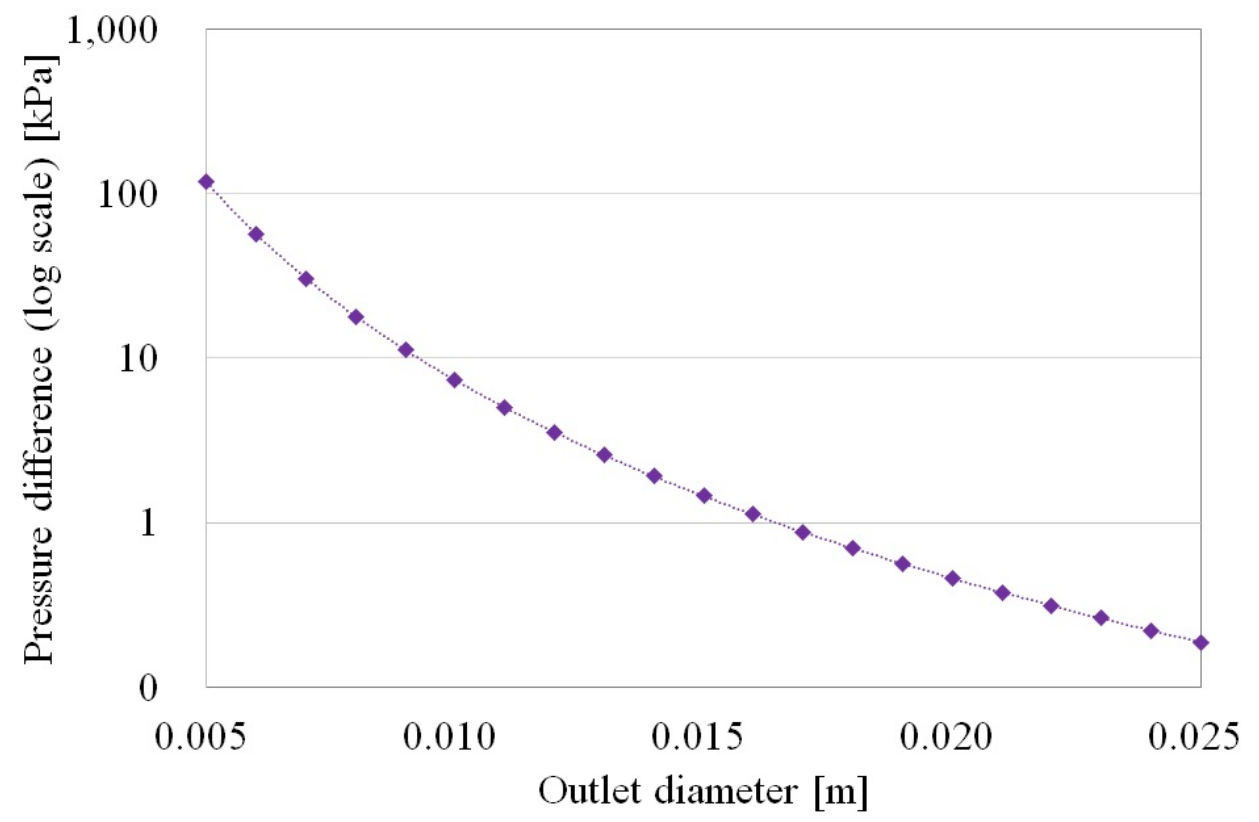

Figure 12. The pressure difference according to the outlet pipe diameter at the sudden contraction part.

\subsection{Experimental Results}

The experiment conducted herein considered various temperatures at the HTSG inlet. The temperature was controlled by installing a heater at the HTSG inlet, and the Reynolds number was varied by changing the flow rate for a given temperature. Figure 13 shows a graph of the temperature variation as a function of the different temperatures and flow rates. The pressure drop increases with the Reynolds number and HTSG inlet temperature due to the increased fluid viscosity at the HTSG inlet.

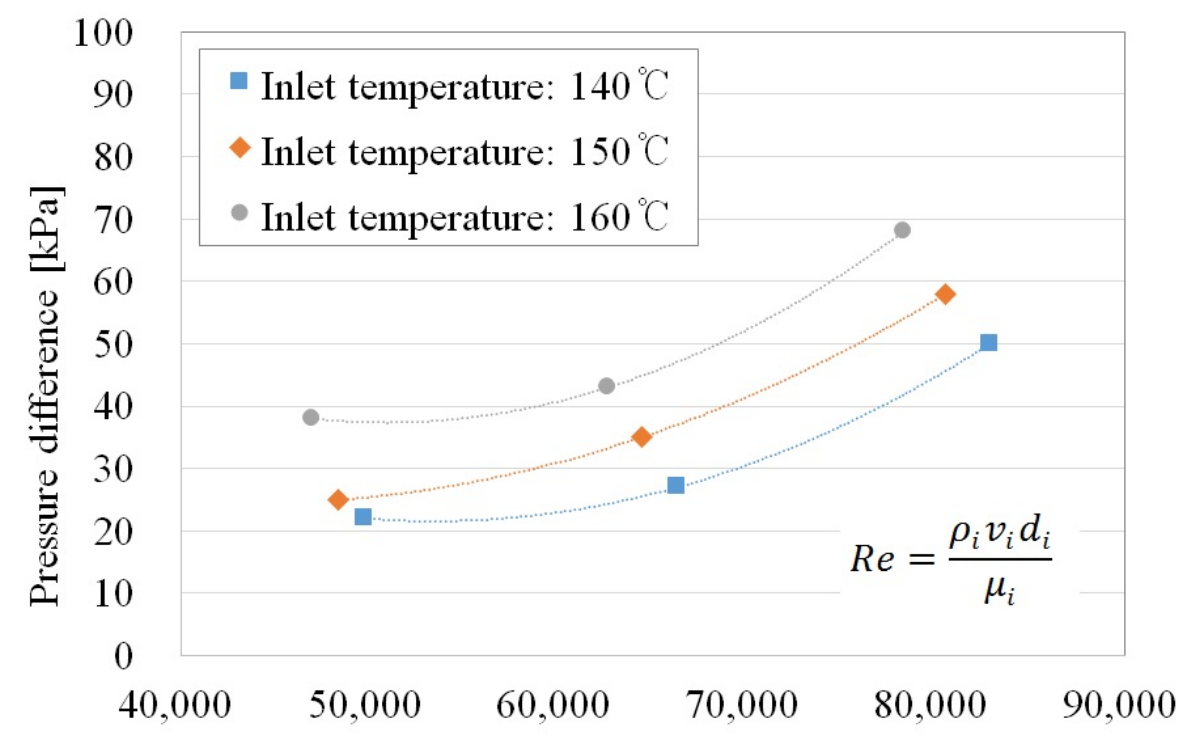

Reynolds number

Figure 13. Comparisons of the pressure difference according to the inlet temperature.

Figure 14 compares the two cases, one where the combustor interior is heated and the other where it is not heated. When the HTSG surface is heated, the internal HTSG temperature increases, and an 
additional pressure drop occurs due to the high-temperature steam residing in the upper region of the HTSG, thus, pushing out the steam that enters through the inlet. Such a phenomenon is herein termed the thermo-extrusion effect, and Figure 15 shows the additional pressure variations due to this effect.

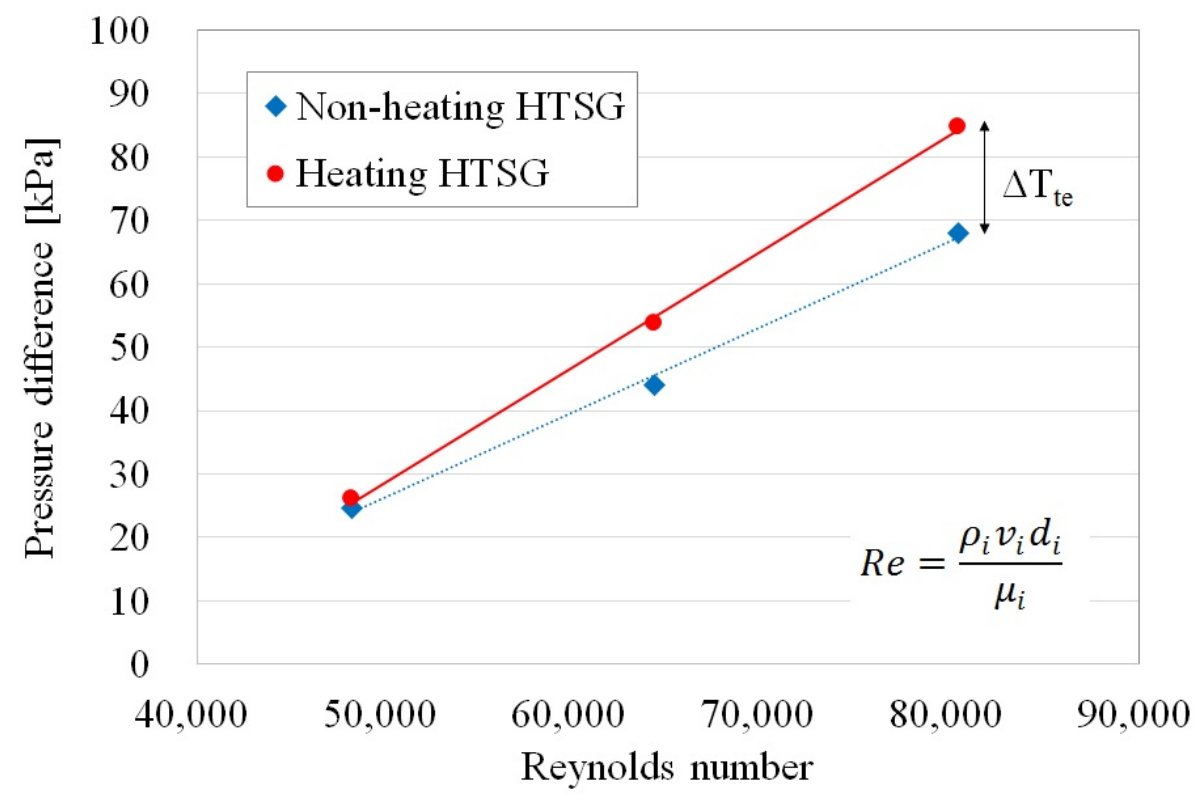

Figure 14. Comparisons of the heating case and non-heating case according to the Reynolds number.

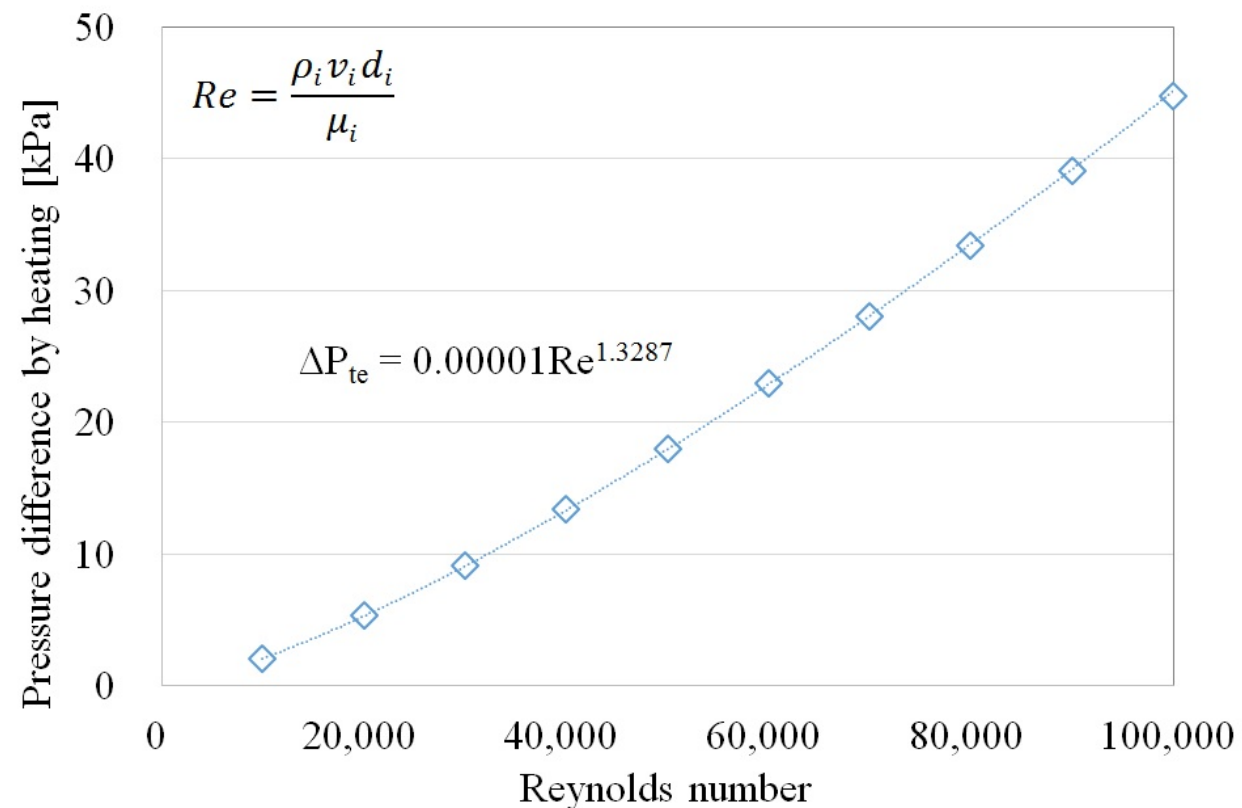

Figure 15. The additional pressure difference by heating (thermo-extrusion effect).

The thermo-extrusion effect is caused by the changes in the density and viscosity as the fluid is heated, as well as due to the fluid velocity change. Therefore, this effect can be described as a function of the Reynolds number (Equation (10)).

$$
\Delta P_{t e}=f(R e)=\alpha R e^{\beta},
$$

where, $\alpha=0.00001$ and $\beta=1.3287$ within the present experimental range. 
Figure 16 shows a comparison of the simulation and experimental results. The dotted line represents the linearized experimental results, and the solid line denotes the linearized simulation results. The discrepancy increases with increasing Reynolds numbers due to thermo-extrusion, the effects of which must be considered in the design process.

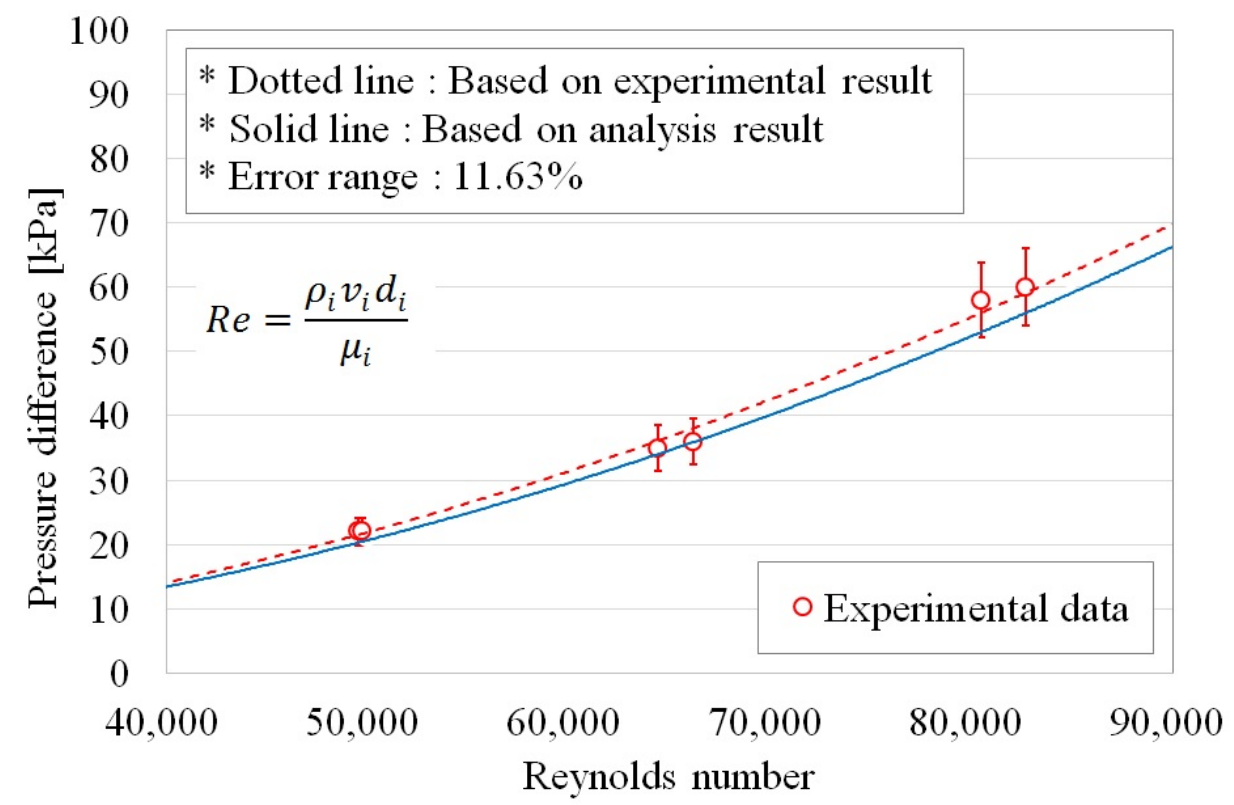

Figure 16. Comparisons of the calculation results and experimental test results (inlet temperature $151.9{ }^{\circ} \mathrm{C}$ approximately).

\section{Conclusions}

In this study, we examined the use of an HTSG to increase the steam temperature and reduce the pressure of the high-temperature steam that is obtained using waste incineration heat for hydrogen production. The structure of the HTSG was designed to facilitate maintenance and repair when inserted into an actual waste incinerator, and the proposed design model was experimentally validated. The structure of the proposed HTSG can be deduced from the pressure changes due to sudden enlargement, swirling flow, vortex flow, and sudden contraction when the fluid temperature remains constant. In the case when the HTSG is heated, however, the pressure variation as a function of temperature must be considered. As a result, the inner diameters of the HTSG inlet and outlet and the entrance angle must be reduced, and the streamline must be lengthened by extending the $H_{t o t}$ of the HTSG body to increase the pressure drop.

Author Contributions: J.J. conceived this paper and proposed the model; S.O. performed the experiments; C.C. advised the proposed paper; S.-R.P. designed the experimental device and contributed to the entire manuscript. All authors provided substantive comments.

Funding: This subject is supported by the "Technologies for Waste Recycling Policy" funded by the Korea Ministry of Environment (MOE) as the "Public Technology Program based on Environmental Policy" (2016000710007).

Conflicts of Interest: The authors declare no conflict of interest.

\section{Nomenclature}

A Area

$C_{p} \quad$ Specfic heat at constant pressure

D Diameter of HTSG body

$d \quad$ Diameter of pipe

$f \quad$ Friction factor

$g \quad$ Gravitational acceleration $\mathrm{m}^{2}$

$\mathrm{kJ} / \mathrm{kg} \cdot \mathrm{K}$

$\mathrm{m}$

$\mathrm{m}$

$\mathrm{m} / \mathrm{s}^{2}$ 


\begin{tabular}{|c|c|c|}
\hline$H$ & Height & $\mathrm{m}$ \\
\hline$h$ & Convection heat transfer coefficient & $\mathrm{kW} / \mathrm{m}^{2} \cdot \mathrm{K}$ \\
\hline$k$ & Conduction heat transfer coefficient & $\mathrm{kW} / \mathrm{m} \cdot \mathrm{K}$ \\
\hline$L$ & Stream line length & $\mathrm{m}$ \\
\hline$\ell$ & Pipe length & $\mathrm{m}$ \\
\hline$\dot{m}$ & Mass flow & $\mathrm{kg} / \mathrm{s}$ \\
\hline$n$ & Number of pitch & EA \\
\hline $\mathrm{Nu}$ & Nusselt number & \\
\hline$P$ & Pressure & $\mathrm{kPa}$ \\
\hline $\operatorname{Pr}$ & Prandtl number & $\mathrm{C}_{\mathrm{p}} \mu / \mathrm{k}$ \\
\hline$Q$ & Heat capacity & $\mathrm{kW}$ \\
\hline $\operatorname{Re}$ & Reynolds number & $\rho v d / \mu$ \\
\hline$T$ & Absolute temperature & K \\
\hline$t$ & Thichness & $\mathrm{m}$ \\
\hline$U$ & Heat transfer coefficient & $\mathrm{kW} / \mathrm{m}^{2} \cdot \mathrm{K}$ \\
\hline$v$ & Velocity & $\mathrm{m} / \mathrm{s}$ \\
\hline \multicolumn{3}{|c|}{ Greek Letters } \\
\hline$\alpha$ & Coefficient of thermo-extrusion & \\
\hline$\beta$ & Exponent of thermo-extrusion & \\
\hline$\Delta$ & Difference & \\
\hline$\eta$ & Heat loss coefficient & \\
\hline$\Theta$ & Angle & $\circ$ \\
\hline$\mu$ & Viscosity & $\mathrm{kg} / \mathrm{ms}$ \\
\hline$\xi$ & Resistance coefficient & \\
\hline$\rho$ & Density & $\mathrm{kg} / \mathrm{m}^{3}$ \\
\hline \multicolumn{3}{|c|}{ Subscriptions } \\
\hline ave & Average & \\
\hline ex & External & \\
\hline HTSG & High temperature steam generator & \\
\hline $\mathrm{i}$ & Inlet & \\
\hline in & Internal & \\
\hline it & Intermediate & \\
\hline $\operatorname{lm}$ & Log mean temperature difference & \\
\hline $\mathrm{mt}$ & Material & \\
\hline $\mathrm{o}$ & Outlet & \\
\hline SC & Sudden contraction & \\
\hline se & Sudden enlargement & \\
\hline sf & Swirling flow & \\
\hline st & Stream line & \\
\hline te & Thermo-extrusion & \\
\hline tot & Total & \\
\hline $\mathrm{vf}$ & Vortex flow & \\
\hline
\end{tabular}

\section{References}

1. Lam, S.S.; Chase, H.A. A Review on Waste to Energy Processes Using Microwave Pyrolysis. Energies 2012, 5, 4209-4232. [CrossRef]

2. Akhator, E.P.; Obanor, A.I.; Igbinomwanhia, D.I. Thermal Analysis of a Small Scale Solid Waste-Fired Steam Boiler for Power Generation in Benin City, Nigeria. Niger. J. Technol. 2016, 35, 555-561. [CrossRef]

3. Yusoff, M.H.M.; Zakaria, R. Combustion of Municipal Solid Waste in Fixed Bed Combustor for Energy Recovery. J. Appl. Sci. 2012, 12, 1176-1180. [CrossRef]

4. Greef, J.D.; Villani, K.; Goethals, J.; Belle, H.V.; Caneghem, J.V.; Vandecasteele, C. Optimising energy recovery and use of chemicals, resources and materials in modern waste-to-energy plants. Waste Manag. 2013, 33, 2416-2424. [CrossRef] [PubMed] 
5. Fehlner, F.P.; Mott, N.F. Low-temperature oxidation. Oxid. Met. 1970, 2, 59-99. [CrossRef]

6. Milovanović, N.; Đorđević, B.; Tatić, U.; Sedmak, S.A.; Štrbački, S. Low-Temperature Corrosion Damage and Repair of Boiler Bottom Panel Tubes. Struct. Integr. Life 2017, 17, 125-131.

7. Marshall, J.; Hoornweg, D.; Eremed, W.B.; Piamonti, G. World Energy Resources Waste to Energy. World Energy Counc. 2016, 5-60. Available online: https:/ / www.worldenergy.org/ (accessed on 29 May 2018).

8. Ryu, C.; Shin, D. Combined Heat and Power from Municipal Solid Waste: Current Status and Issues in South Korea. Energies 2013, 6, 45-57. [CrossRef]

9. Zieliński, A.; Dobrzański, J.; Purzyńska, H.; Sikora, R.; Dziuba-Kałuża, M.; Kania, Z. Evaluation of Creep Strength of Heterogeneous Welded Joint in HR6W Alloy and Sanicro 25 Steel. Arch. Metall. Mater. 2017, 62, 2057-2064. [CrossRef]

10. Zeng, Z.; Oliveira, J.P.; Bu, X.; Yang, M.; Li, R.; Wang, Z. Laser Welding of BTi-6431S High Temperature Titanium Alloy. Metals 2017, 7, 504. [CrossRef]

11. Wright, J.K.; Carroll, L.J.; Cabet, C.; Lillo, T.M.; Benz, J.K.; Simpson, J.A.; Lloyd, W.R.; Chapman, J.A.; Wright, R.N. Characterization of elevated temperature properties of heat exchanger and steam generator alloys. Nucl. Eng. Des. 2012, 251, 252-260. [CrossRef]

12. Dewa, R.T.; Kim, S.J.; Kim, W.G.; Kim, E.S. Effect of Strain Range on the Low Cycle Fatigue in Alloy 617 at High Temperature. Metals 2017, 7, 54. [CrossRef]

13. Wu, J.; Liu, X. Recent Development of SOFC Metallic Interconnect. J. Mater. Sci. Technol. 2010, 26, $293-305$. [CrossRef]

14. Silva, F.S.; Souza, T.M. Novel materials for solid oxide fuel cell technologies: A literature review. Int. J. Hydrogen Energy 2017, 42, 26020-26036. [CrossRef]

15. Zhou, W.; Jia, Z.; Qin, J.; Bao, W.; Yu, B. Experimental study on effect of pressure on heat sink of n-decane. Chem. Eng. J. 2014, 243, 127-136. [CrossRef]

16. Beek, M.C.V.; Rindt, C.C.M.; Wijers, J.G.; Steenhoven, A.A.V. Analysis of Fouling in Refuse Waste Incinerators. Heat Transf. Eng. 2010, 22, 22-31. [CrossRef]

17. Gnielinski, V. Neue Gleichungen für den Wärme- und den Stoffübergang in turbulent durchströmten Rohren und Kanälen. Forschung im Ingenieurwesen 1974, 41, 8-16. [CrossRef]

18. Petukhov, B.S. Heat Transfer and Friction in Turbulent Pipe Flow with Variable Physical Properties. Adv. Heat Transf. 1970, 6, 503-564. [CrossRef]

19. Idelchik, I.E. Handbook of Hydraulic Resistance, 3rd ed.; Begell House: New York, NY, USA, 1996; pp. 1-130.

20. Prasad, S.S.; Satish, G.; Panduranga, G. Comparison of Flow Analysis through Sudden Contraction and Enlargement of Pipes by Providing Smooth Corners. Int. J. Eng. Trends Technol. 2015, 25, 205-211. [CrossRef]

21. Weisbach, J. Lehrbuch der Ingenieur- und Maschinen-Mechanik. In Theoretische Mechanik; Vieweg und Sohn: Braunschweig, Germany, 1845; Volume 1, pp. 532-560. 